\title{
Composition of Amphiboles in the Tremolite-Ferro- Actinolite Series by Raman Spectroscopy
}

\author{
Danilo Bersani ${ }^{1}$ **1D , Sergio Andò ${ }^{2}$, Laura Scrocco ${ }^{3}$, Paolo Gentile ${ }^{2}$, Emma Salvioli-Mariani ${ }^{3}$, \\ Laura Fornasini $^{1}$ (D) and Pier Paolo Lottici ${ }^{1}$ (D) \\ 1 Department of Mathematical, Physical and Computer Sciences, University of Parma, Parco Area delle \\ Scienze 7/A, 43124 Parma, Italy \\ 2 Department of Earth and Environmental Sciences, University of Milano-Bicocca, Piazzale della Scienza 4, \\ 20126 Milano, Italy \\ 3 Department of Chemistry, Life Sciences and Environmental Sustainability, University of Parma, Parco Area \\ delle Scienze 157/A, 43124 Parma, Italy \\ * Correspondence: danilo.bersani@unipr.it
}

Received: 12 June 2019; Accepted: 13 August 2019; Published: 16 August 2019

check for updates

\begin{abstract}
Amphiboles are an important family of rock forming minerals, whose identification is crucial in provenance studies as well as in many other fields of geology, archaeology and environmental sciences. This study is aimed to find a quick way to characterize Ca-amphiboles in the tremolite $\left(\mathrm{Ca}_{2} \mathrm{Mg}_{5} \mathrm{Si}_{8} \mathrm{O}_{22}(\mathrm{OH})_{2}\right)$-ferro-actinolite $\left(\mathrm{Ca}_{2} \mathrm{Fe}_{5} \mathrm{Si}_{8} \mathrm{O}_{22}(\mathrm{OH})_{2}\right)$ series. Raman spectroscopy is established as technique to perform non-destructive and quick analysis, with micrometric resolution, able to give the composition in terms of $\mathrm{Mg} /\left(\mathrm{Mg}+\mathrm{Fe}^{2+}\right)$ ratio. To exploit the method, a preliminary characterization is performed by Scanning Electron Microscopy coupled with Energy-dispersed X-ray Spectroscopy (SEM-EDS). Two independent methods to evaluate the composition from the Raman data (aiming to an accuracy of about $5 \%$ ), using the low-wavenumbers part of the spectrum and the $\mathrm{OH}$ stretching bands, are developed. The application of the proposed method to micro-Raman mappings and the possible use of handheld Raman spectroscopy to have compositional information on Ca-amphiboles are discussed.
\end{abstract}

Keywords: Raman spectroscopy; amphiboles; tremolite; actinolite; heavy minerals

\section{Introduction}

Amphiboles are a widespread family of rock forming minerals with general formula $\left(\mathrm{A}_{0-1} \mathrm{~B}_{2} \mathrm{C}_{5} \mathrm{~T}_{8} \mathrm{O}_{22} \mathrm{~W}_{2}\right)$; they are the most common heavy minerals in Alpine-Himalayan orogenic belts formed by continental collision [1]. Amphiboles are formed under a wide range of pressures, temperatures and chemical environments, and their composition reflects the crystallization conditions providing important information on the metamorphic evolution of source areas [2]. Some chemical properties of detrital minerals are directly revealed by optical features that are quickly identified and recorded during grain counting [3]. Amphiboles, and in particular detrital amphiboles, thus represent accurate provenance tracers that can be profitably used in provenance studies. In the tremolite-ferro-actinolite series, $\square \mathrm{Ca}_{2} \mathrm{Mg}_{5} \mathrm{Si}_{8} \mathrm{O}_{22}(\mathrm{OH})_{2}-\square \mathrm{Ca}_{2} \mathrm{Fe}^{2+}{ }_{5} \mathrm{Si}_{8} \mathrm{O}_{22}(\mathrm{OH})_{2}$, the members can be distinguished by $\mathrm{X}=\mathrm{Mg} /\left(\mathrm{Mg}+\mathrm{Fe}^{2+}\right)$ ratio. The compositional range of tremolite extends from $\square \mathrm{Ca}_{2} \mathrm{Mg}_{5} \mathrm{Si}_{8} \mathrm{O}_{22}(\mathrm{OH})_{2}$ to $\square \mathrm{Ca}_{2} \mathrm{Mg}_{4.5} \mathrm{Fe}^{2+}{ }_{0.5} \mathrm{Si}_{8} \mathrm{O}_{22}(\mathrm{OH})_{2}(0.9 \leq X \leq 1)$ actinolite extends from $\square \mathrm{Ca}_{2} \mathrm{Mg}_{<4.5} \mathrm{Fe}^{2+}>0.5 \mathrm{Si}_{8} \mathrm{O}_{22}(\mathrm{OH})_{2}$ to $\square \mathrm{Ca}_{2} \mathrm{Mg}_{2.5} \mathrm{Fe}^{2+}{ }_{2.5} \mathrm{Si}_{8} \mathrm{O}_{22}(\mathrm{OH})_{2}(0.5<X<0.9)$, and ferro-actinolite extends from $\square \mathrm{Ca}_{2} \mathrm{Mg}_{<2.5} \mathrm{Fe}^{2+}>2.5 \mathrm{Si}_{8} \mathrm{O}_{22}(\mathrm{OH})_{2}$ to $\square \mathrm{Ca}_{2} \mathrm{Fe}^{2+}{ }_{5} \mathrm{Si}_{8} \mathrm{O}_{22}(\mathrm{OH})_{2} X<0.5$ [4].

A great variety of techniques can be applied for the identification of single crystal in sediments: optical microscope studies [5], microprobe analysis [6], Raman spectroscopy [7], Fourier transform infrared spectroscopy and X-ray diffraction [8]. In provenance studies and heavy-mineral analysis 
of sediments, Raman discrimination of amphiboles is not yet widely applied [9]. Raman databases, mostly based on the $\mathrm{OH}$ stretching bands (3500-3800 $\mathrm{cm}^{-1}$ spectral range), are sparse in literature. In this paper we have checked the advantages of the Raman spectroscopic approach and discussed limitations applying this technique on real samples and with different spectrometers in the laboratory and in the field. This study is intended as a complementary tool to the classical optical studies performed by polarizing microscope and it aims to help to distinguish, in a quick and representative way, the different suites of Ca-amphiboles commonly found in modern sediments. An additional objective is the reduction of the bias introduced by the different skill of each operator, always present during the optical assessment of amphibole colour in heavy-mineral slides. When analyzing rocks in the amphibolite-facies, the distinction between common blue-green hornblende and rare actinolite is important. It can be assessed by a well established and time consuming chemical analysis by SEM-EDS, but it is not easy to be achieved only through the optical properties collected during observation with a mineralogical microscope and by different operators. Extinction angle varies with chemistry but its measurement is affected by the orientation of the mineral in grain mounts. Even the different grain size (15-500 micron), normally observed under the microscope, strongly influences the colors and pleochroism of amphiboles for the same chemistry. This can be a major issue, as an example, during the analysis of detrital amphiboles in marine scientific expeditions where the suite of amphiboles to be recognized over a big sample requires a huge effort to achieve a proper identification. The discrimination made only by traditional optical techniques between tremolite and cummingtonite or between actinolite and grunerite requires a careful identification of subtle differences in birefringence and extinction, needing a very expert eye, with a high risk of errors.

In this work, we took advantage from the collections of heavy minerals from sediments, available at the Department of Earth and Environmental Sciences (DISAT) in Milano-Bicocca (Milano, Italy). The huge number of slides (more than 5500) prepared in more than 15 years for heavy mineral analyses, from samples collected in different geological settings and countries all around the world [10], contain thousands of amphiboles embedded in Canada Balsam. For this study, we selected Alpine mineral samples in the tremolite-ferro-actinolite series, sometimes called nephrite series from the name of the green rock nephrite comprising massive cryptocrystalline felted calcic amphiboles of the homonymous series [11]. The characterization was performed by micro-Raman spectroscopy and Scanning Electron Microscopy coupled with Energy-dispersed X-ray Spectroscopy (SEM-EDS), to obtain the relationship between the Raman spectra and the $X=\mathrm{Mg} /\left(\mathrm{Mg}+\mathrm{Fe}^{2+}\right)$ ratio, with the aim to obtain a method for the estimation of the composition directly from the Raman spectrum. The attempt to obtain the composition of members of the nephrite series, and in particular the cation ratio $X$ by means of micro-Raman spectroscopy is not new. We start from the fundamental work on the cation distribution on amphiboles of Wang et al. [12] and from the application of Raman micro-spectroscopy on the study of jades proposed by Chen et al. [11] to develop a quick method for the identification of nephrite using both low and high wavenumber regions of the spectrum. The use of the method to realize composition maps in zoned crystals of actinolite is shown.

In addition, we evaluated the possible use of mobile instrumentation. This can extend the application fields for the Raman analysis of the calcic amphiboles, for example, in the field archaeology and conservation science. Nephrite is the main component of the so-called "true-jade" (the other main type of jade has pyroxene nature, being composed by the clinopyroxene jadeite $\left.\mathrm{Na}\left(\mathrm{Al}, \mathrm{Fe}^{3+}\right) \mathrm{Si}_{2} \mathrm{O}_{6}\right)$. The identification of the composition of nephrite is then of great interest in archaeology and art history, giving information useful for provenance and authentication purposes. The use of a mobile Raman spectrometer can allow the study of archaeologic jade objects $[13,14]$ in situ and in fast and completely non-invasive way. In addition, fibrous tremolite is considered an asbesto mineral, very dangerous for human health. The use of mobile Raman spectroscopy can allow a quick identification directly in the natural environment [15]. 


\section{Materials and Methods}

The analyzed samples are twenty minerals in the tremolite-ferro-actinolite series, coming from different localities in the Alps, supposed to cover all the compositional range from nearly pure tremolite to ferro-actinolite terms (Table 1). The samples were embedded in araldite resin and polished, in order to perform SEM-EDS analysis. On each sample, the same points were analyzed by SEM-EDS and micro-Raman spectroscopy according to the following strategy. We measured with SEM-EDS 8/10 points for each sample. Then we selected only homogeneous points in order to maintain the average compositional dispersion lower than 0.025 (taken as the uncertainty for SEM-EDS measurements). Then micro-Raman measurements (nearly 10) were performed as nearest as possible to the selected points. A new set of raw mineral specimens, in part overlapping the previous one, was used for the analysis with the portable Raman system.

Table 1. Provenance of the twenty amphiboles analyzed with SEM-EDS and micro-Raman spectroscopy.

\begin{tabular}{cc}
\hline Sample No. & Provenance \\
\hline 1 & Villa Lake, Valle d'Ayas, Valle d'Aosta, Italy \\
$2,3,4$ & Pineta di Primolo, Valmalenco, Lombardia, Italy \\
$5,6,19$ & Miage Glacier, Val Veny, Valle d'Aosta, Italy \\
7,8 & Valle Formazza, Piemonte, Italy \\
$9,11,12$ & Alpe di Caneto, Valle Vigezzo, Piemonte, Italy \\
10 & Val di Basso, Valle Vigezzo, Piemonte, Italy \\
13 & Passo dei Laghi, Valle Devero, Piemonte, Italy \\
14 & Tirolo, Alto-Adige, Italy \\
16,21 & Campolongo, Canton Ticino, Switzerland \\
17 & Pizzo Rosso, Valle Aurina, Alto Adige, Italy \\
18 & Alpe Rosso, Valle Vigezzo, Piemonte, Italy \\
20 & Pizzo Bandiera, Valle Devero, Piemonte, Italy \\
\hline
\end{tabular}

Non-polarized micro-Raman spectra have been obtained on the mineral fragments embedded in the resin stab in nearly backscattering geometry with a Horiba LabRam apparatus (HORIBA Scientific, Kyoto, Japan), equipped with an Olympus microscope (Olympus, Tokyo, Japan) with 10×, 50×, ULWD $50 \times$ and $100 \times$ objectives and a motorized $x-y$ stage. The $632.8 \mathrm{~nm}$ line of a He-Ne laser and the $473.1 \mathrm{~nm}$ line of a doubled Nd:YAG laser were used as excitation; the $632.8 \mathrm{~nm}$ line was mostly used to obtain high resolution spectra in the low wavenumber range $\left(100-1200 \mathrm{~cm}^{-1}\right)$, whereas the $473.1 \mathrm{~nm}$ source was utilized for higher efficiency in the detection of the $\mathrm{OH}$ stretching signals of the $\mathrm{OH}$ groups in the range $3000-4000 \mathrm{~cm}^{-1}$. Laser power (less than $1 \mathrm{~mW}$ on the sample) was controlled by means of density filters, to avoid heating effects. The minimum lateral resolution was about $1 \mu \mathrm{m}$ (with the $100 \times$ objective), the depth resolution was set to few micrometers by means of a confocal hole. The spectral resolution was $\sim 2 \mathrm{~cm}^{-1}$ (at $632.8 \mathrm{~nm}$ ) and $\sim 4 \mathrm{~cm}^{-1}$ (at $473.1 \mathrm{~nm}$ ). The system was calibrated using the $520.6 \mathrm{~cm}^{-1}$ Raman band of silicon. In the high wavenumber range, the spectra were further calibrated using spectral lamps: in particular, for the $\mathrm{OH}$ stretching region, with the $473.1 \mathrm{~nm}$ laser, we used the main emission lines of $\mathrm{Hg}$ in fluorescent bulbs $(546.07,576.96$ and $579.07 \mathrm{~nm})$.

The spectra were collected using 100× and 50× ULWD (ultra long working distance) objectives. Several points for each samples were measured, with repeated acquisitions of $60 \mathrm{~s}$ each. A simple polynomial background subtraction was performed on each spectrum with LabSpec ${ }^{\circledR}$ software. The same program was used to perform spectral deconvolution, using Gauss-Lorentzian functions, to determine position, width and intensity (amplitude and area) of the Raman bands. With excitation at $632.8 \mathrm{~nm}$, the position of the bands was obtained with an uncertainty better than $0.5 \mathrm{~cm}^{-1}$.

Raman maps were obtained on a rectangular matrix of $9 \times 11$ points in an area of $40 \times 75$ square micrometers. The acquisition time for each point was $30 \mathrm{~s}$. A gray tone image was obtained by associating the lightness to the position of the actinolite main peak in the range $660-680 \mathrm{~cm}^{-1}$. A smoothing in the digital map was performed for a best comparison with the microscope photograph of the same area. 
In addition, Raman spectra have been obtained on some raw samples, not embedded in resins, with a high resolution confocal Raman microscope (Renishaw inVia Reflex, Renishaw, Wotton-under-Edge, UK), equipped with a Leica DM2500 polarizing microscope (Leica Microsystems, Wetzlar, Germany), with a 50x LWD (long working distance) objective and motorized $x-y$ stages. Spectra were obtained by the $532 \mathrm{~nm}$ line of a solid-state laser with a power of few $\mathrm{mW}$ at the sample, spectral resolution of $\pm 0.5 \mathrm{~cm}^{-1}$ and acquisition time of $2 \mathrm{~min}$.

Raman measurements were also made with a portable instrument: a handheld Enspectr RaPort ${ }^{\circledR}$ spectrometer, equipped with a $532 \mathrm{~nm}$ laser (max power $30 \mathrm{~mW}$, used at half power) with a spectral resolution of $\sim 8 \mathrm{~cm}^{-1}$. The laser spot is approximatively $0.5 \mathrm{~mm}$. The wide measurement range (100-4000 $\mathrm{cm}^{-1}$ ) makes this tool a good choice for the in situ study of hydrous silicates [16,17]. The instrument has a weight of nearly $2 \mathrm{Kg}$ and is operated by a laptop through USB 2.0 connection. Typical acquisition times are of the order of $60 \mathrm{~s}$, but some dark samples required longer acquisition times.

SEM-EDS measurements have been performed on the mineral samples embedded in resin stab. Samples were analyzed for their major elements with a Tescan VEGA TS Univac 5136 XM scanning electron microscope coupled with an EDAX Genesis 4000 XMS Imaging 60 SEM-EDS at the University of Milano-Bicocca, Milano, Italy, under an electron beam accelerated at $20 \mathrm{kV}$, with $250 \mathrm{~nm}$ spot size and a current of $190 \pm 1 \mathrm{pA}$, The quantification was obtained using natural standards (Astimex Scientific Ltd, Toronto, ON, Canada). Counting time was $100 \mathrm{sec}$ plus deadtime (25\%). ZAF matrix correction was applied. The $\mathrm{Fe}^{3+}$ content was calculated according to Hawthorne et al. [4] and end member according to IMA classification $[4,18]$.

\section{Results and Discussion}

The chemical composition of the samples of the main set obtained by SEM-EDS is reported in Table 2. All the investigated samples belong to the nephrite series of calcic amphiboles, and range from pure tremolite (sample \#21) to Fe-actinolite (sample \#17). Some samples of tremolite contain small amount of iron (up to $3.26 \mathrm{wt} \% \mathrm{FeOt}$ ) and aluminium (up to $3.68 \mathrm{wt} \% \mathrm{Al}_{2} \mathrm{O}_{3}$ ). The actinolite samples show a variable concentration of iron (5.27-13.16 wt \% FeOt) with $\mathrm{Fe}^{3+}$ ranging from 0 to 0.325 apfu. Some actinolites have small content of chromium (up to $0.80 \mathrm{wt} \% \mathrm{Cr}_{2} \mathrm{O}_{3}$ ).

Table 2. Representative compositions of the investigated amphiboles obtained by SEM-EDS. Act = actinolite, Trm $=$ tremolite, $\mathrm{Fe}$-Act $=$ ferro-actinolite.

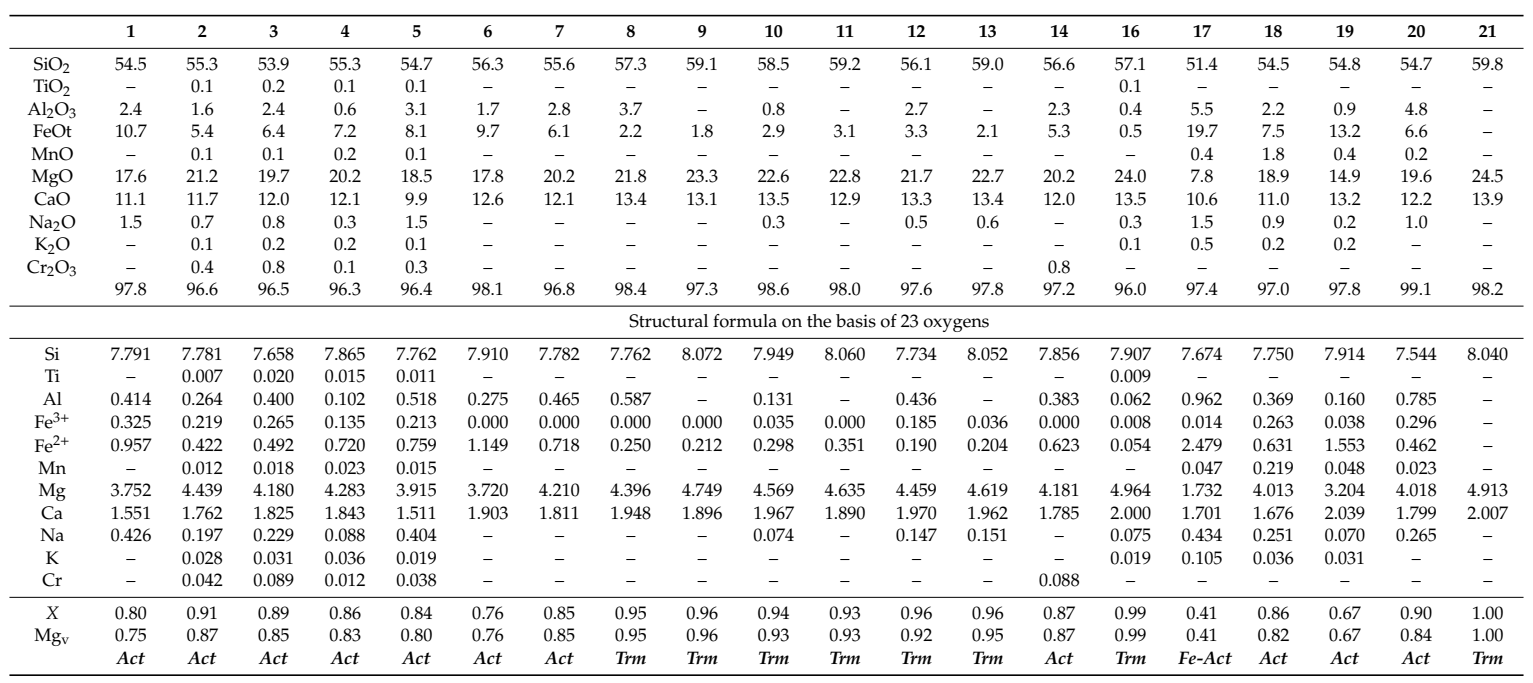

The Raman spectrum of tremolite and actinolite between 100 and $1100 \mathrm{~cm}^{-1}$ (Figure 1) is characterized by the typical features of the spectra of amphibole minerals [19-21]. A possible schematic representation is the following: under $200 \mathrm{~cm}^{-1}$, lattice vibrations; between 300 and $600 \mathrm{~cm}^{-1}, \mathrm{Mg}-\mathrm{OH}$ and $\mathrm{Fe}-\mathrm{OH}$ vibrations, $\mathrm{Si}-\mathrm{O}-\mathrm{Si}$ bending motions and $\mathrm{OH}^{-}$librations; between 650 and $750 \mathrm{~cm}^{-1}$, 
the strong $\mathrm{Si}-\mathrm{O}-\mathrm{Si}$ symmetric stretching, over $750 \mathrm{~cm}^{-1}$, the $\mathrm{O}-\mathrm{Si}-\mathrm{O}$ symmetric stretching and the $\mathrm{O}-\mathrm{Si}-\mathrm{O}$ and $\mathrm{Si}-\mathrm{O}-\mathrm{Si}$ asymmetric stretching motions.

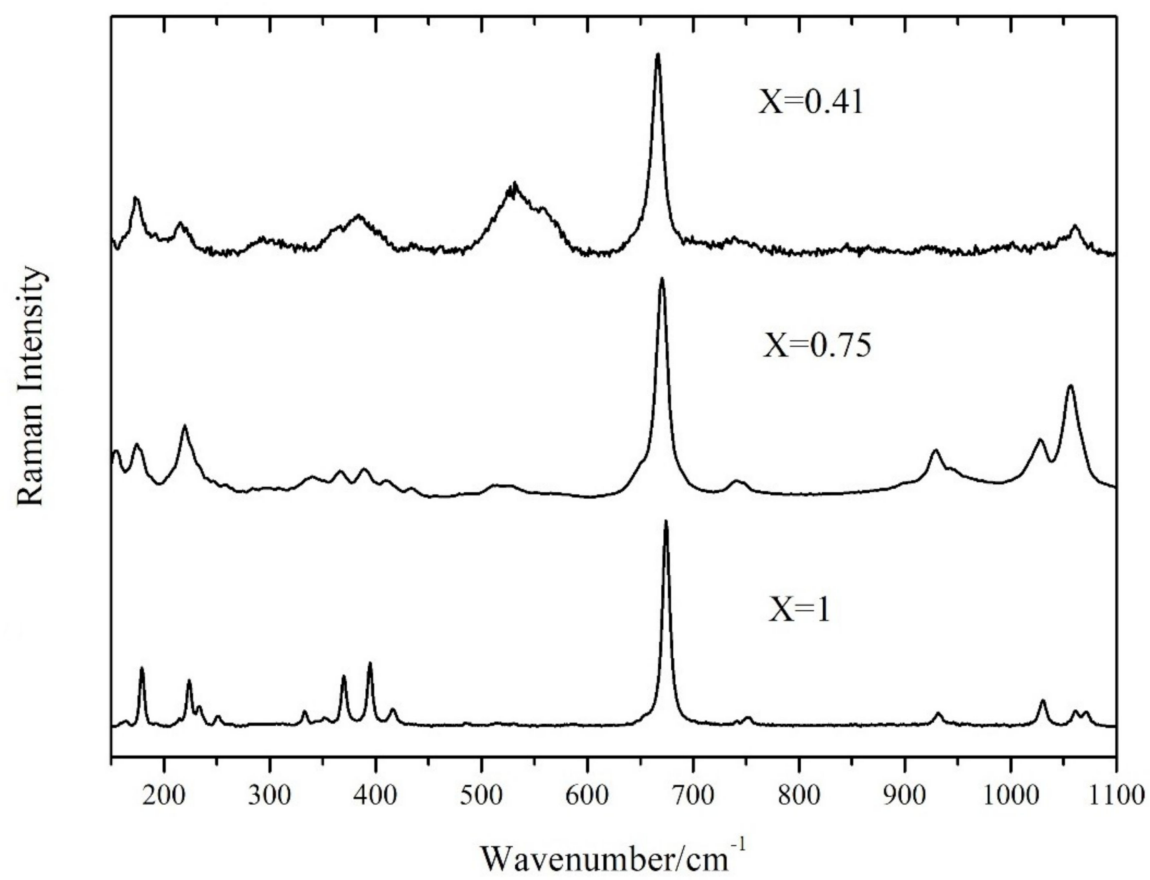

Figure 1. Raman spectra at low wavenumbers of different minerals of tremolite Fe-actinolite series with different $X$ ratios.

As $\mathrm{Mg}$ is substituted by $\mathrm{Fe}^{2+}$, the Raman bands broaden; the main band at nearly $670 \mathrm{~cm}^{-1}$ changes its width (FWHM) from $9 \mathrm{~cm}^{-1}$ for pure tremolite $(X=1)$ to $18 \mathrm{~cm}^{-1}$ for Fe-actinolite $(X=0.41)$. Some of the minor peaks are no more resolved and merge into broad features.

The main feature of the Raman spectra in the low-wavenumber region, at nearly $675 \mathrm{~cm}^{-1}$, is the Si-O-Si symmetrical stretching (Figure 1) with $\mathrm{A}_{\mathrm{g}}$ symmetry. This mode, when substituting $\mathrm{Mg}^{2+}$ with the heavier $\mathrm{Fe}^{2+}$, downshifts from $675 \mathrm{~cm}^{-1}$ in pure tremolite to $667 \mathrm{~cm}^{-1}$ in Fe-rich actinolite $(X=0.41$, at the border with Fe-actinolite). A linear trend of the wavenumber with composition is expected by the one-mode behavior usually shown by $\mathrm{Si}-\mathrm{O}$ vibrations in chain silicates and in particular in amphiboles [22]. This trend is clearly evidenced in Figure 2. A linear interpolation allows to obtain a simple formula relating the position of the main $\mathrm{A}_{\mathrm{g}}$ band with the $\mathrm{X}$ ratio as obtained by SEM-EDS data (see Table 2): $X=0.066 \times(v-659.3)$, where $v$ is expressed in $\mathrm{cm}^{-1}$ and 659.33 is the $v$ value for $X=0$, as obtained from the interpolation. The least squares linear fitting procedure returned a value of the coefficient $R^{2}=0.962$ and the standard errors on the slope (0.003). The intercept is zero with a standard error of 0.04 . The standard error on $X$ obtained from the interpolation is 0.03 .

Only two points (not used in the interpolation procedure) are markedly far from the straight line, related to two samples presenting specific analysis problems. The first one is related to sample \#5, very small with a large compositional variability (e.g., $\mathrm{Fe}^{2+}$ amount ranges from 0.58 to 1.27 in different points) and showing a small amount of Mn, able to occupy M4 as well as M1, M2, M3 sites. The second point is related to sample \#10, highly zoned with large variations in composition. For these two samples, the main source of error is the compositional gradient near the analysed points; a small error in the position can produce a big change in the $X$ value or in the wavenumber of the main Raman peak giving useless results. The parameters obtained from the linear interpolation represent a first tool useful to determine the composition of minerals in the nephrite series from a quick Raman spectrum. This method requires a very good wavenumber calibration of the spectrometer, but it can be also used when noisy or weak spectra are obtained, being based only on the position of the most intense Raman peak. 


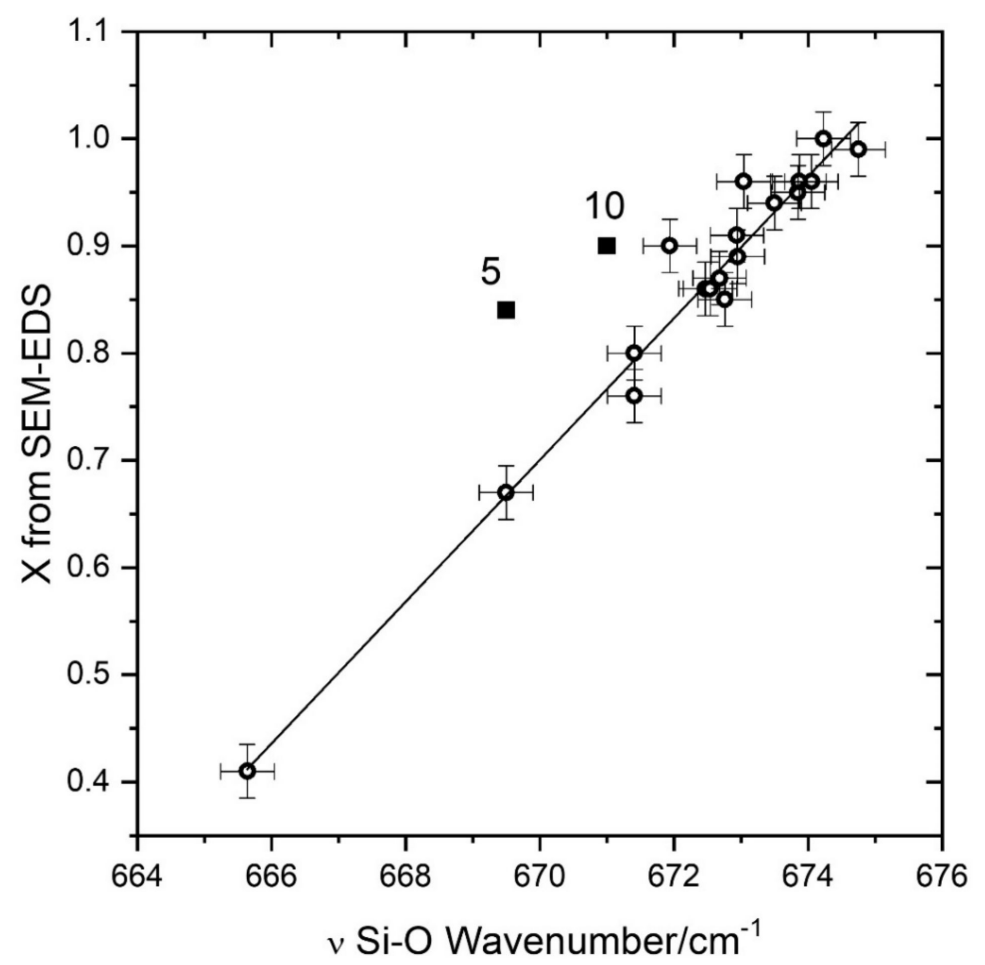

Figure 2. Relation between the wavenumber $v$ of the $\mathrm{A}_{\mathrm{g}}$ main Raman peak at low wavenumber and the chemical composition $X=\mathrm{Mg} /\left(\mathrm{Mg}+\mathrm{Fe}^{2+}\right)$. The straight line represents the result of the linear interpolation: $X=0.066 \times(v-659.3)$. The numbered points are the outliers described in the text.

We verified the shift to lower frequencies of the main $A_{g}$ peak with the increase of iron, by making a micrometric Raman map $(10 \times 5$ points $)$ on a zoned, needle-shaped, tremolite crystal coming from Alpe Rosso (Vigezzo Valley, Italy). As visible in the microscope image (Figure 3 top) the green color, due to the presence of iron, increases from left to right (nearly along the maximum elongation of the crystal). The grey color map (Figure 3 bottom) represents the position of the $\mathrm{A}_{\mathrm{g}}$ main band: lower lightness means lower wavenumber (higher Fe amount). As expected, the intensity of green color in the picture is well paralleled by the dark parts of the Raman map.

In the high-wavenumbers region (3600-3700 $\mathrm{cm}^{-1}$ ) a number of $\mathrm{OH}$ stretching bands (from 1 to 4 ) is present. The number and relative intensity of these bands depend on the $X$ value. This is due to the fact that in amphiboles the $\mathrm{OH}$ groups are bonded to 3 sites indicated as $\mathrm{C}$ in the general chemical formula. Theses C-sites are usually occupied in nephrites by $\mathrm{Mg}^{2+}$ and $\mathrm{Fe}^{2+}$ ions. The frequency of the $\mathrm{OH}$ stretching vibrations is then influenced by the population of the 3 nearest $\mathrm{C}$-sites $[11,12,20,23]$. The $\mathrm{OH}$ stretching mode shows a two-mode behaviour, meaning that for every different atomic configuration, a different Raman peak arises [20]. When only Mg is present (as in pure tremolite), only one peak (at $3675 \mathrm{~cm}^{-1}$ ) is observed. As the amount of iron increases, the other peaks, related to different combinations of $\mathrm{Fe}^{2+}$ and $\mathrm{Mg}^{2+}$ in the sites close to $\mathrm{OH}$, arise at lower wavenumbers (Figure 4). We built a simple statistical model, using the binomial distribution, based on the hypothesis that the 3 sites close to $\mathrm{OH}$ are randomly occupied by $\mathrm{Fe}^{2+}$ and $\mathrm{Mg}^{2+}$ ions, with a probability proportional to their relative amount. The area of the $\mathrm{OH}$ Raman bands at about $3675 \mathrm{~cm}^{-1}(\mathrm{OH}$ surrounded by $3 \mathrm{Mg}^{2+}$ ions) will be proportional to $X^{3}$, while the area of the band at $3660 \mathrm{~cm}^{-1}(\mathrm{OH}$ surrounded by $2 \mathrm{Mg}^{2+}$ and $1 \mathrm{Fe}^{2+}$ ions) will be proportional to $3 X^{2}(1-X)$. The ratio between the two bands is then $A_{12}=X /[3(1-X)]$. In this way we obtain another relation useful to estimate the $X$ value from the Raman spectrum: $X=\left(\mathrm{A}_{12}\right) /\left(1 / 3+\mathrm{A}_{12}\right)$. 

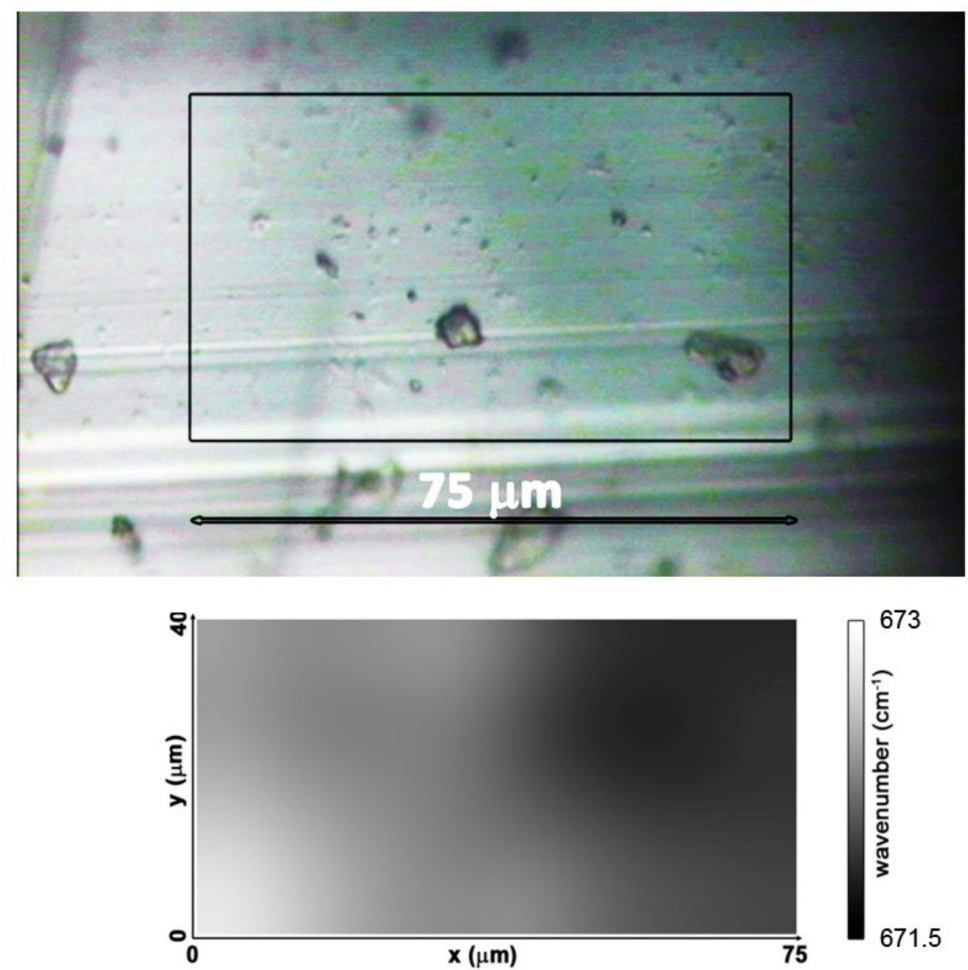

Figure 3. Microscope image (top) and Raman map (bottom) representing the shift of the main $\mathrm{Ag}_{\mathrm{g}}$ band obtained on a zoned actinolite crystal.

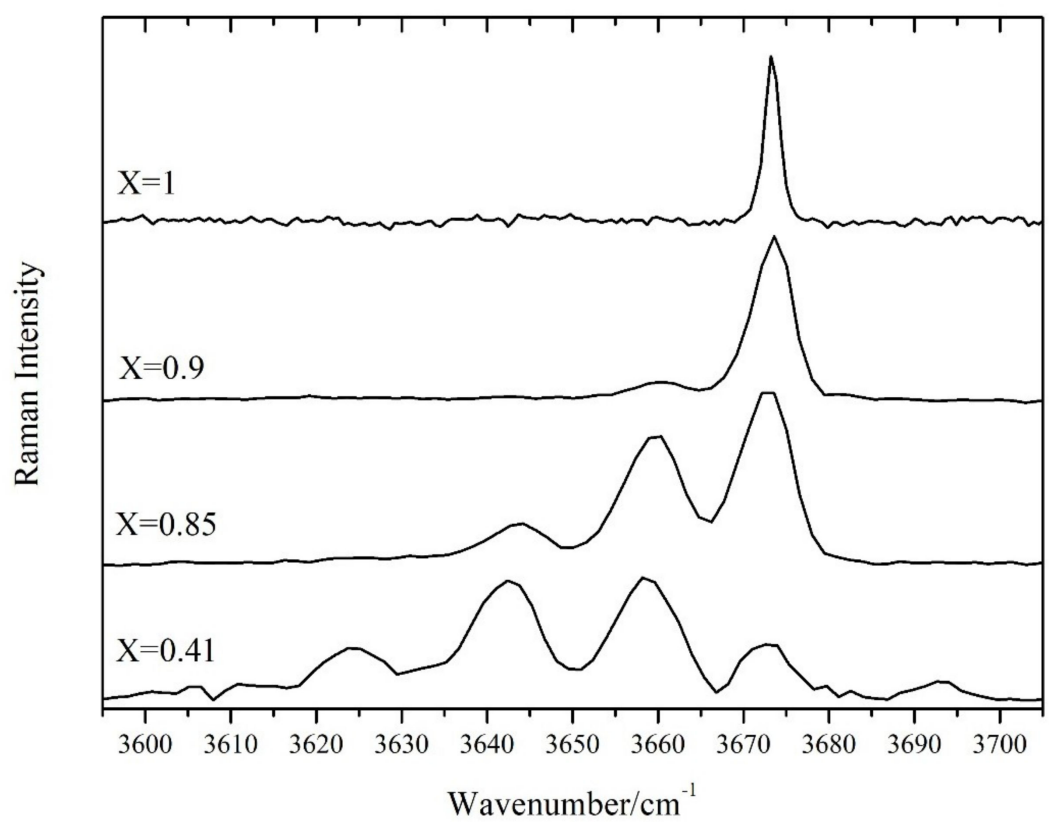

Figure 4. Raman spectra at high wavenumbers of minerals of tremolite Fe-actinolite series with different $\mathrm{X}$ ratios.

In Figure 5 the composition ( $\mathrm{X}$ value) estimated from the areas of the $\mathrm{OH}$ bands and that measured by SEM-EDS is shown: a good agreement is observed, with a very slight tendency of the "OH bands" method to underestimate X. Only for a sample (\#3), with composition far from ideal nephrite, with many extra ions, the obtained values differ more than 0.1 . The standard error on $\mathrm{X}$ obtained with this method, calculated from the differences between Raman (OH bands) and SEM-EDS data is 0.04 . 


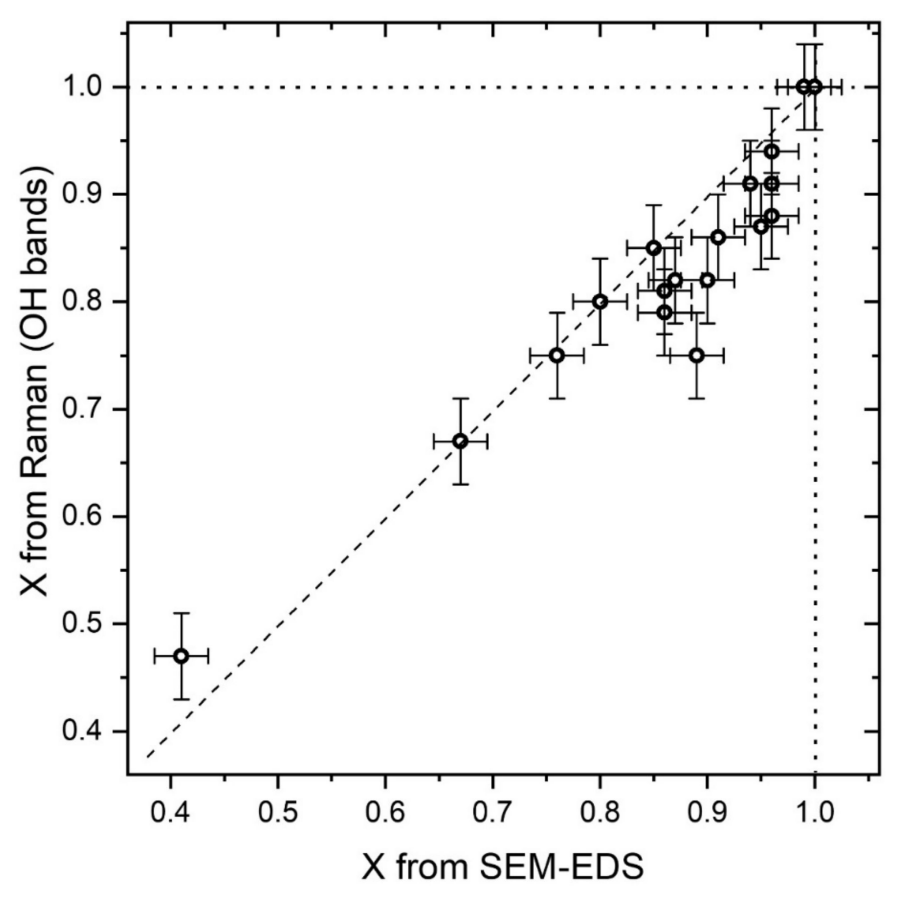

Figure 5. Comparison between the compositions ( $X$ ratios) of the tremolite Fe-actinolite samples estimated by the $\mathrm{OH}$ stretching bands and those obtained by SEM-EDS. The dashed lines (for $X=1.0$ and for equal values) are drawn for visual aid.

The simple equation $X=\left(A_{12}\right) /\left(1 / 3+A_{12}\right)$, gives results comparable with those obtained by the equation proposed by Chen et al. [11] but the latter is based on the intensity of all the $\mathrm{OH}$ features, while our calculation requires only the intensity of two peaks, usually the most intense ones in the Mg-rich samples and easy to measure. The choice to work with only two peaks was made in order to obtain compositional information even using noisy spectra, with just the most intense peaks emerging. This can be important when working on the field, with real samples, or maybe in a museum when the object can be analysed only with a contactless technique and for a short time. A disadvantage is that this method strongly relies on the hypothesis of a random distribution of the cations, that could be not true. However, the cross-check with the other methods (the low-wavenumber method presented before and the method proposed by Chen et al. [11]) indicate that the possible deviations from the randomness are not relevant. The evaluation of the composition $(X$ value) from the ratio of the intensities of the $\mathrm{OH}$ stretching bands is not affected by the wavenumber calibration of the instrument and can be made independently of that obtained from the position of the main $\mathrm{Ag}_{\mathrm{g}}$ peak.

The comparison between the two proposed methods is shown by Figure 6 where the $X$ values obtained starting from the position of the main Raman band at nearly $670 \mathrm{~cm}^{-1}$ and from the area ratio of the OH Raman stretching bands are compared. The two methods give comparable results, but the $X$ values obtained with the "OH stretching" method are in most cases slightly lower (the average difference is 0.05 ) than those obtained by the "Si-O stretching" one. This difference is probably due to a slight underestimation provided by the "OH stretching" method, as already suggested by Figure 5 . Deviations of the real amphiboles from the theoretical behaviour expected by our statistical model as well as the non-flat spectral answer of the spectrometer can be between the causes of this difference. On the other hand, $X$ values obtained by the "Si-O stretching" method have a better dispersion (see Figure 2), as expected from an empirical procedure. For that reason they can be considered more reliable, but only when a perfect calibration of the spectrometer is provided. 


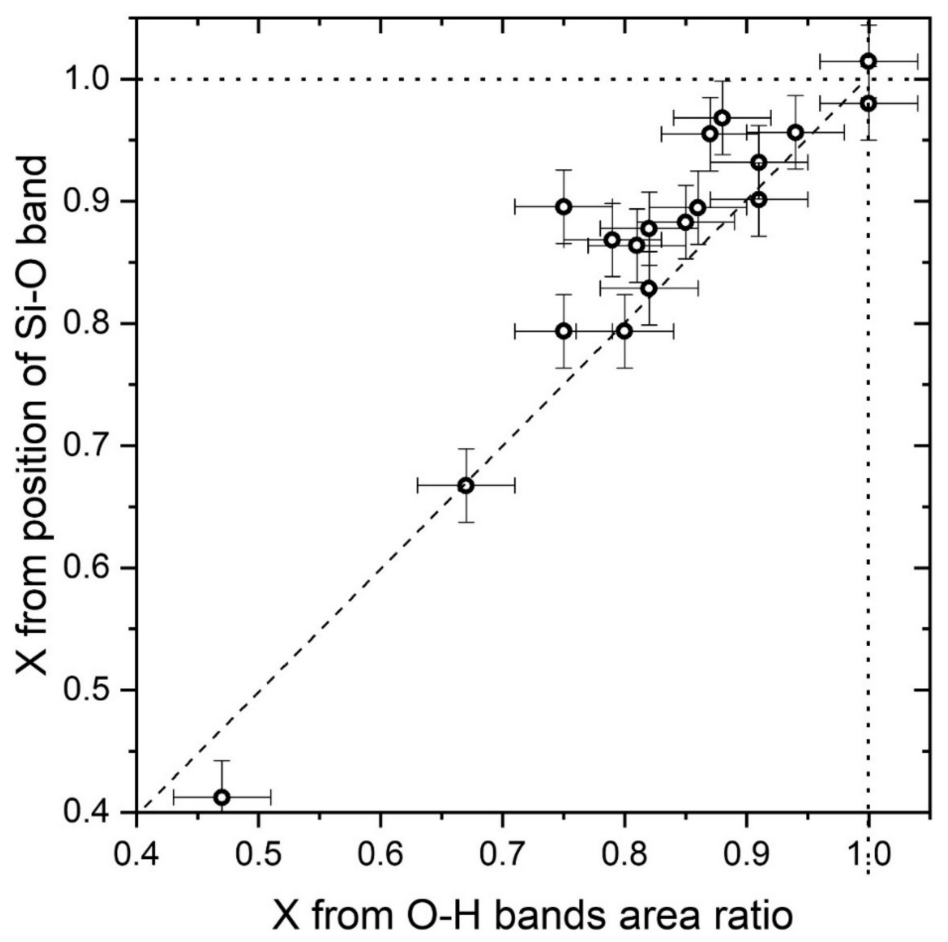

Figure 6. Comparison between the $X$ values obtained starting from the position of the main Raman band at nearly $670 \mathrm{~cm}^{-1}$ and from the area ratio of the $\mathrm{OH}$ Raman stretching bands. The dashed lines (for $X=1.0$ and for equal values) are drawn for visual aid.

To evaluate the possible effect of $\mathrm{Fe}^{3+}$ on the position of the $\mathrm{Si}-\mathrm{O}$ stretching main band and on the area of the $\mathrm{OH}$ stretching bands, we replotted the graphs and recalculated the parameters using the total amount of iron $\left(\mathrm{Fe}_{\text {total }}\right)$ instead of $\mathrm{Fe}^{2+}$. The obtained trends are very similar and the obtained parameters (including the estimated $X$ values) show variations largely smaller than the calculated uncertainty. For that reason, and because the definition of tremolite and actinolite depends on the $\mathrm{Mg} /\left(\mathrm{Mg}+\mathrm{Fe}^{2+}\right)$ ratio, we decided to not include $\mathrm{Fe}^{3+}$ in the calculations.

The possibility to obtain compositional information on the $\mathrm{X}$ value in situ, for example directly on the outcrops or in a museum environment, using a compact portable instrument, was then evaluated. Due to the impossibility to analyze micrometric crystals or very small felted clusters, a partly different set of minerals was used. Of course, due to the large spot, possible thin zonations are averaged.

A comparison between some spectra obtained using the micro-Raman and the mobile Raman spectrometers is reported in Figure 7 (low wavenumber range) and Figure 8 (high wavenumber range).

It is clearly visible (Figure $7 \mathrm{a}-\mathrm{c}$ ) that in the low wavenumber range the spectra obtained with the handheld spectrometer are of good quality, often comparable with those obtained with the micro-Raman apparatus, despite the lower spectral resolution. The mobile instrument has a fixed geometry and cannot be calibrated with the required precision. For this reason the position of the Raman bands is not enough accurate to obtain the $X$ composition from the wavenumber of the main $A_{g}$ mode. However, when a reference line is present (e.g. the strong $546 \mathrm{~nm}$ line of a common fluorescent tube, appearing at $485 \mathrm{~cm}^{-1}$ in the spectrum), the difference in position of the main $\mathrm{Ag}_{\mathrm{g}}$ mode between iron rich ("Serifos") and iron poor ("Valmalenco") terms is clearly detectable (Figure 7d).

In the high wavenumber range (Figure 8), the spectra obtained with the mobile spectrometer on the nephrite minerals are very weak and noisy, because the $\mathrm{OH}$ stretching bands are in a region near the limit of the spectral window measured by our handheld spectrometer, with a very bad signal to noise ratio. Even with very long acquisition times (several minutes) it is difficult to observe clean $\mathrm{OH}$ stretching peaks. Nevertheless, the distribution of the intensities between the various peaks well reflects that obtained with the micro-Raman spectrometer. Even if the quality of the spectra is not 
enough to give a quantitative estimation of $X$, it is still possible to distinguish between iron-rich and magnesium-rich terms of the series.

One of the macroscopic samples (Serifos) used for the test of the mobile Raman spectrometer show the spectral features of a very Fe-rich ferro-actinolite. For that reason we decided to measure its composition even with SEM-EDS, obtaining $X=0.31$. The $X$ value calculated from the position of the main $\mathrm{Si}-\mathrm{O}$ stretching band measured with a micro-Raman spectrometer $\left(v=664.2 \mathrm{~cm}^{-1}\right)$ is $X=0.32$, in very good agreement with SEM-EDS. To estimate the $X$ value from the areas of the $\mathrm{OH}$ stretching bands in Fe-rich samples, it is possible to use the ratio $\left(\mathrm{A}_{43}\right)$ between the two strongest bands related to $(\mathrm{Fe}, \mathrm{Fe}, \mathrm{Fe})$ and $(\mathrm{Fe}, \mathrm{Mg}, \mathrm{Mg})$ configurations to calculate $1-X=\left(\mathrm{A}_{43}\right) /\left(1 / 3+\mathrm{A}_{43}\right)$. For the Serifos sample we obtained $X=0.25$, not far from the value obtained by SEM-EDS. These results confirm the validity of both Raman-based methods in the Fe-rich region of the series.
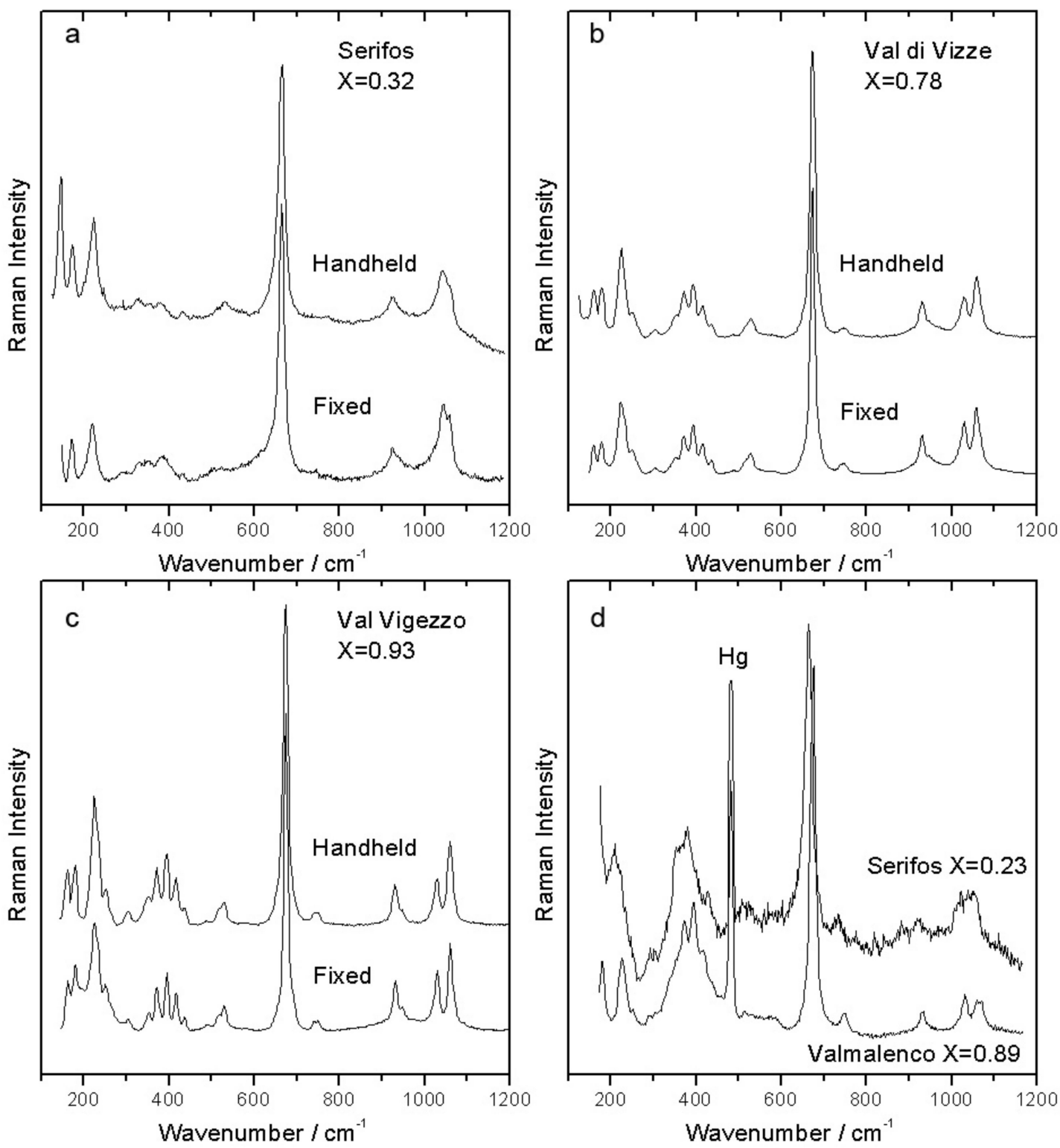

Figure 7. (a-c): comparison between spectra obtained on different samples in the low-wavenumbers region with fixed and handheld Raman spectrometers; (d): comparison between spectra obtained on Fe-rich and Fe-poor samples with the handheld spectrometer in the low-wavenumber region. $\mathrm{Hg}=\mathrm{Hg}$ emission line of a fluorescent tube. The $X$ values reported are obtained by micro-Raman (fixed Raman) data. 

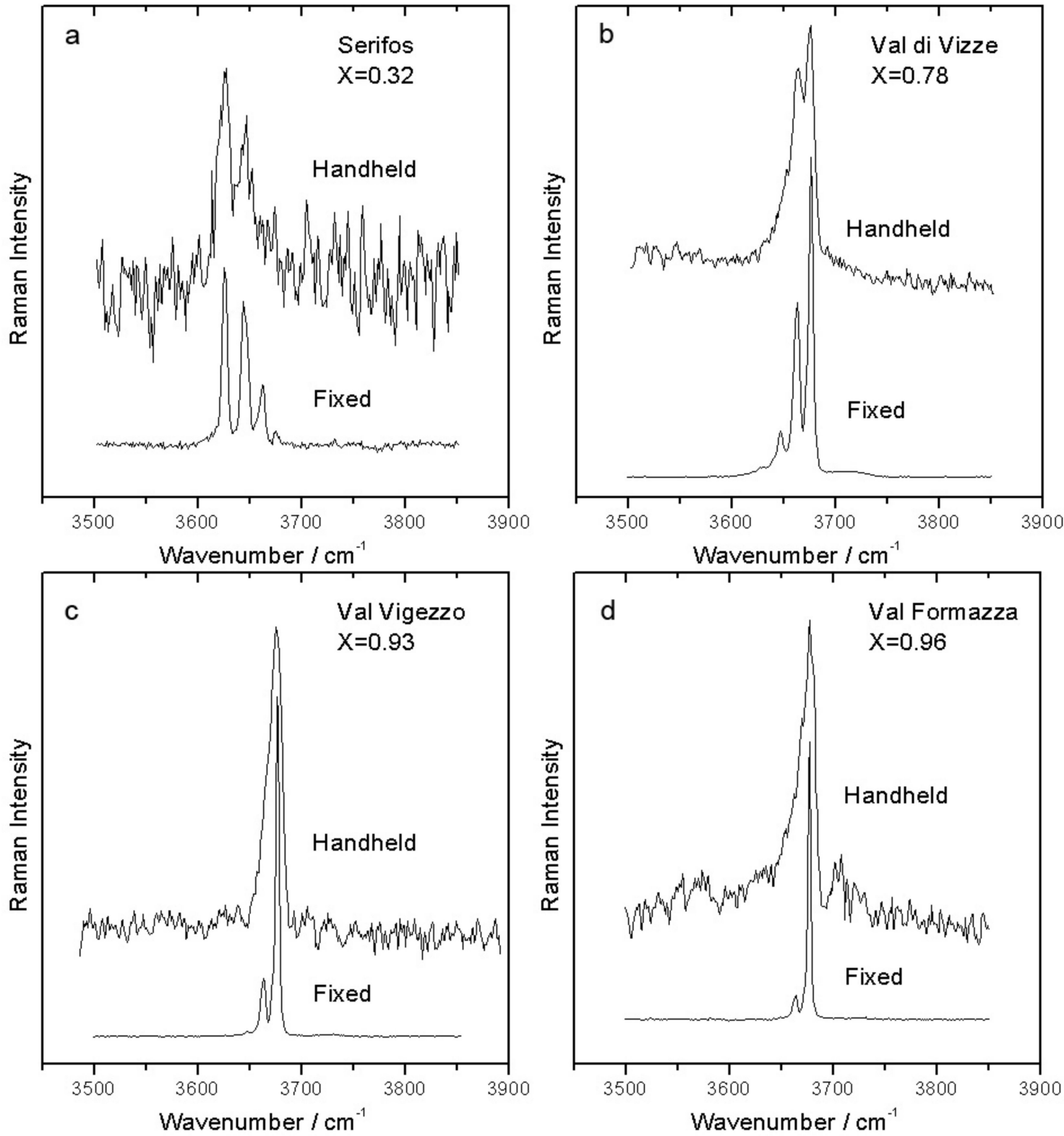

Figure 8. $(\mathbf{a}-\mathbf{c})$ : comparison between spectra obtained on different samples in the $\mathrm{OH}$-stretching region with fixed and handheld Raman spectrometers, (d): comparison between spectra obtained on Fe-rich and Fe-poor samples with the handheld spectrometer in the $\mathrm{OH}$-stretching region. The $\mathrm{X}$ values reported in this figures are obtained by micro-Raman (fixed Raman) data.

\section{Conclusions}

We obtained two simple and independent methods to evaluate the composition of nephritic minerals from their Raman spectrum. The first one, based on the position of the main $\mathrm{A}_{\mathrm{g}}$ band, shows a better sensitivity and linearity with the changes of the $X$ value. On the other hand, the second method, based on the ratio of the areas of the two most intense $\mathrm{OH}$ stretching bands, is nearly insensitive to the spectrometer calibration. The two methods are consistent and can be chosen depending on the experimental setup and the quality of the signal in the different spectral regions.

The fast and easy to automatize calculation of the $X$ value on Raman micro-maps allows to study compositional variations on microscopic scale directly on crystals, fibers or archaeological items, without requiring any preparation of the samples. 
The identification of minerals of the tremolite Fe-actinolite series and the discrimination between Fe-rich and Mg-rich terms from their Raman spectra is immediate also for not skilled operators. This study shows that it is possible to obtain the most important information even using very compact (handheld) mobile Raman spectrometers; this result is very important to extend the use of Raman spectroscopy for the identification of Ca amphiboles not only to routine analysis, but also for on-the-field applications in sedimentology, petrography, archaeometry and environmental analysis.

Author Contributions: Conceptualization, D.B. and S.A.; Formal analysis, P.G. and E.S.-M.; Investigation, D.B., S.A., L.S. and P.G.; Methodology, D.B. and S.A.; Visualization, L.F.; Writing—original draft, D.B.; Writing—review \& editing, S.A. and P.P.L.

Funding: This research received no external funding

Conflicts of Interest: The authors declare no conflict of interest.

\section{References}

1. Garzanti, E.; Doglioni, C.; Vezzoli, G.; Andò, S. Orogenic Belts and Orogenic Sediment Provenance. J. Geol. 2007, 115, 315-334. [CrossRef]

2. Andò, S.; Morton, A.; Garzanti, E. Metamorphic grade of source rocks revealed by chemical fingerprints of detrital amphibole and garnet. In Sediment Provenance Studies in Hydrocarbon Exploration and Production; Scott, R.A., Smyth, H.R., Morton, A.C., Richardson, N., Eds.; Geological Society London Special Publications: London, UK, 2014; Volume 386, pp. 351-371.

3. Garzanti, E.; Vezzoli, G.; Lombardo, B.; Andò, S.; Mauri, E.; Monguzzi, S.; Russo, M. Collision-orogen provenance (Western and Central Alps): Detrital signatures and unroofing Trends. J. Geol. 2004, 112, 145-164. [CrossRef]

4. Hawthorne, F.C.; Oberti, R.; Harlow, G.E.; Maresch, W.V.; Martin, R.F.; Schumacher, J.C.; Welch, M.D. Nomenclature of the amphibole supergroup. Am. Miner. 2012, 97, 2031-2048. [CrossRef]

5. Cascalho, J. Provenance of Heavy Minerals: A Case Study from the WNW Portuguese Continental Margin. Minerals 2019, 9, 355. [CrossRef]

6. Liang, W.; Garzanti, E.; Andò, S.; Gentile, P.; Resentini, A. Multimineral fingerprint of Transhimalayan and Himalayan sources of Indus-derived Thal Desert sand (Central Pakistan). Minerals 2019, 9, 457. [CrossRef]

7. Lünsdorf, N.K.; Kalies, J.; Ahlers, P.; Dunkl, I.; Von Eynatten, H. Semi-Automated Heavy-Mineral Analysis by Raman Spectroscopy. Minerals 2019, 9, 385. [CrossRef]

8. Hahn, A.; Vogel, H.; Andó, S.; Garzanti, E.; Kuhn, G.; Lantzsch, H.; Schüürman, J.; Vogt, C.; Zabel, M. Using Fourier transform infrared spectroscopy to determine mineral phases in sediments. Sediment. Geol. 2018, 375, 27-35. [CrossRef]

9. Andò, S.; Garzanti, E. Raman spectroscopy in heavy mineral studies. In Sediment Provenance Studies in Hydrocarbon Exploration and Production; Scott, R.A., Smyth, H.R., Morton, A.C., Richardson, N., Eds.; Geological Society London Special Publications: London, UK, 2014; Volume 386, pp. 395-412.

10. Garzanti, E.; Andò, S. Plate tectonics and heavy-mineral suites of modern sands. In Heavy Minerals in Use; Mange, M.A., Wright, D.T., Eds.; Elsevier: Amsterdam, The Netherlands, 2007; Volume 58, pp. 741-763.

11. Chen, T.-H.; Calligaro, T.; Pagès-Camagna, S.; Menu, M. Investigation of Chinese archaic jade by PIXE and $\mu$ Raman spectrometry. Appl. Phys. A 2004, 79, 177-180. [CrossRef]

12. Wang, A.; Dhamelincourt, P.; Turrell, G. Raman microspectroscopic study of the cation distribution in amphiboles. Appl. Spectrosc. 1988, 42, 1441. [CrossRef]

13. Wang, R.; Zhang, W.-S. Application of Raman spectroscopy in the nondestructive analyses of ancient Chinese jades. J. Raman Spectrosc. 2011, 42, 1324-1329. [CrossRef]

14. Casadio, F.; Douglas, J.G.; Faber, K.T. Noninvasive methods for the investigation of ancient Chinese jades: An integrated analytical approach. Anal. Bioanal. Chem. 2007, 387, 791-801. [CrossRef] [PubMed]

15. Rinaudo, C.; Belluso, E.; Gastaldi, D. Assessment of the use of Raman spectroscopy for the determination of amphibole asbestos. Miner. Magaz. 2004, 68, 455-465. [CrossRef]

16. Jehlička, J.; Culka, A.; Bersani, D.; Vandenabeele, P. Comparison of seven portable Raman spectrometers: Beryl as a case study. J. Raman Spectrosc. 2017, 48, 1289-1299. [CrossRef] 
17. Petriglieri, J.R.; Laporte-Magoni, C.; Gunkel-Grillon, P.; Tribaudino, M.; Bersani, D.; Sala, O.; Le Mestre, M.; Vigliaturo, R.; Bursi Gandolfi, N.; Salvioli-Mariani, E. Mineral fibres and environmental monitoring: A comparison of different analytical strategies in New Caledonia. Geosci. Front. Ophiolites 2019, in press. [CrossRef]

18. Leake, B.E.; Wooley, A.R.; Arps, C.E.; Birch, W.D.; Gilbert, M.C.; Grice, J.D.; Hawthorne, F.C.; Kato, A.; Kisch, H.J.; Krivovichec, V.G.; et al. Nomenclature of amphibole. Report of the Subcommittee on Amphiboles of the International Mineralogical Association Commission on New Minerals and Mineral names. Eur. J. Miner. 1997, 9, 623-651. [CrossRef]

19. Apopei, A.I.; Buzgar, N. The Raman study of amphiboles. An. Ştiinţifice Univ. Cuza Iaşi Geol. 2010, 1, 57-83.

20. Leissner, L. Crystal Chemistry of Amphiboles Studied by Raman Spectroscopy. Master's Thesis, Mineralogisch-Petrographisches Institut, Universität Hamburg, Hamburg, Germany, 2014.

21. Leissner, L.; Schlüter, J.; Horn, I.; Mihailova, B. Exploring the potential of Raman spectroscopy for crystallochemical analyses of complex hydrous silicates: I. Amphiboles. Am. Miner. 2015, 100, 2682-2694. [CrossRef]

22. Andrut, M.; Gottschalk, M.; Melzer, S.; Najorka, J. Lattice vibrational modes in synthetic tremolite-Sr-tremolite and tremolite-richterite solid solutions. Phys. Chem. Miner. 2000, 27, 301-309. [CrossRef]

23. Sbroscia, M.; Della Ventura, G.; Iezzi, G.; Sodo, S. Quantifying the A-site occupancy in amphiboles: A Raman study in the $\mathrm{OH}$-stretching region. Eur. J. Miner. 2018, 30, 429-436. [CrossRef]

(C) 2019 by the authors. Licensee MDPI, Basel, Switzerland. This article is an open access article distributed under the terms and conditions of the Creative Commons Attribution (CC BY) license (http://creativecommons.org/licenses/by/4.0/). 